Arch. Vet. Scienc. 3(1):25-30, 1998

Printed in Brazil

\title{
ASPECTOS ETIOLÓGICOS E EPIDEMIOLÓGICOS DO ABORTO EQÜINO*
}

\section{NEI MOREIRA ${ }^{1}$; ERNESTO RENATO KRÜGER ${ }^{2}$; JOSÉ FRANCISCO G. WARTH ${ }^{3}$; SÔNIA MARIA BIESDORF ${ }^{2}$; MARIELA M.M. GOULARTE ${ }^{2}$; ROMILDO ROMUALDO WEISS ${ }^{4}$}

${ }^{1}$ Departamento de Fisiologia, Campus Palotina, Universidade Federal do Paraná, Curso de Pós-Graduação em Zoologia SCB-UFPR. ${ }^{2}$ Centro de Diagnóstico Marcos Enriette: Secretaria de Estado da Agricultura e do Abastecimento. ${ }^{3}$ Departamento de Patologia Básica, Setor de Ciências Biológicas da Universidade Federal do Paraná. ${ }^{4}$ Departamento de Medicina Veterinária, Setor de Ciências Agrárias, UFPR.

ASTRACT - This research was undertaken with the aim of establishing the main causes of equine abortion in the Curitiba area. It has been established that during the period of three years occurred a total of 9.2 per cent abortions among 674 gestations studied. From 50 aborted fetuses, different biological material was collected for bacteriology, virus and histopathology analysis. A total of 4.5 per cent of twin abortions were observed among 132 cases of abortions studied. The equine Herpesvirus type 1 has been successfully isolated from 4 cases, among 21 fetuses studied. On the other hand, 44.7 per cent from 38 fetuses studied were considered positive for bacteriological testing. The most frequent bacteria recovered were Streptococcus spp., Klebsiella spp., Escherichia coli, Pseudomonas spp. and Staphylococcus spp. The alterations found in the histological examination of the majority of bacteriological and virological abortion cases were desccribed.

Key Words: Equine abortion, reproduction, equine Herpesvirus.

RESUMO - Para a investigação das causas de aborto eqüino na região de Curitiba, realizou-se a coleta e processamento do material de casos de aborto para bacteriologia, virologia e histologia; e um levantamento estatístico geral dos casos de aborto. Durante três anos, foram acompanhadas 674 gestações, das quais 9,2\% resultaram em aborto. Com relação a abortos gemelares, verificou-se um índice de 4,5\% em um total de 132 casos analisados. O material de 21 fetos foi processado com o intuito de isolar-se o Herpesvírus eqüino tipo 1, obtendo-se o isolamento em 4 casos $(19,0 \%)$. Foram examinados para bacteriologia um total de 38 fetos, dos quais $44,7 \%$ foram considerados bacteriologicamente positivos. As bactérias isoladas com maior freqüência foram: Streptococcus spp., Klebsiella spp., Escherichia coli, Pseudomonas spp. e Staphylococcus spp.. Foram descritas as alterações encontradas no exame histológico da maioria dos casos de aborto de origem bacteriana e viral.

Palavras-Chave: Aborto eqüino, reprodução, Herpesvírus eqüino.

\section{Introdução}

O aborto em éguas é fonte de sérios prejuízos econômicos, sendo que a taxa em criações de Puro Sangue Inglês tem sido estimada como superior a $12 \%$. O tema aborto eqüino tem sido bastante revisado, o que é uma evidência de que este problema apresenta-se de forma constante para veterinários, que são consultados, na tentativa de encontrar-se a causa e para a prevenção de ocorrências subseqüentes (ACLAND, 1987). Segundo WITHERSPOON (1984), o aborto e a mortalidade perinatal representam expressivas perdas devido ao grande valor comercial dos potros.

Apenas com o conhecimento completo das

\footnotetext{
* Extrato de Tese de Mestrado de Nei Moreira, Curso de PósGraduação em Ciências Veterinárias, UFPR.

Com auxílios da Coordenação do Aperfeiçoamento do Pessoal de Ensino Superior - CAPES - e do Conselho Nacional do Desenvolvimento Científico e Tecnológico - CNPq. Correspondência para Prof. Nei Moreira Caixa Postal, 54 85.950-000 Palotina, PR. E-mail: moreira@ bio ufpr br
}

causas de aborto, pode o clínico ajudar a reduzir as perdas de seu cliente ou ajudá-lo a aceitar e compreender aquelas perdas que ocorrem, inevitavelmente, a qualquer criador (PRICKETT, 1970). A probabilidade da causa de um aborto ser determinada é sempre maior se ambos, o feto e a placenta, forem examinados em uma necropsia facilitada. Devido às restrições de tempo, dinheiro e disponibilidade dos serviços, o veterinário é, freqüentemente, obrigado a realizar uma necropsia a campo (ACLAND, 1987).

Ênfase tem sido dada aos últimos estágios de gestação, com achados patológicos no feto ou suas membranas, que variam com seus mecanismos de resistência (PRICKETT, 1970). Numerosos fatores etiológicos são responsáveis por doença fetal e aborto subseqüente. Estes fatores podem ser divididos em dois grupos: infecciosos e não infecciosos. Entretanto, em alguns casos, pode-se encontrar a confluência desses fatores no mesmo feto. Muitos fatores não infecciosos podem predispor a égua e o feto a doenças infecciosas e algumas doenças infecciosas podem predispor a 
égua e o feto a microrganismos oportunistas (SWERCZEK, 1991a).

No Brasil, em 1966, NILSON e CORRÊA isolaram pela primeira vez o vírus do aborto eqüino em hamsters lactentes, a partir do fígado de feto abortado. $\mathrm{O}$ aborto eqüino devido ao Herpesvírus eqüino na Região Sul do Brasil foi também relatado por WEIBLEN et al., em 1994.

A prevalência encontrada de anticorpos contra Herpesvírus eqüino tipo 1 (HVE 1) em eqüinos tem sido descrita para algumas regiões do Brasil, como o trabalho de MODOLO et al. (1989), em que encontraram $17,6 \%$ de soropositividade trabalhando com eqüinos da região noroeste do Estado de São Paulo, através da prova de fixação de complemento. Além do percentual observado por VARGAS (1989) no Estado do Rio Grande do Sul $(84,7 \%)$ e por FERNANDES (1988) no Estado de São Paulo $(57,3 \%)$ em animais não vacinados registra-se também a freqüência de eqüinos com anticorpos anti Herpesvírus eqüino tipo 1, equivalente a $17,7 \%$, encontrada por MOREIRA (1992) na região de Curitiba, Estado do Paraná.

Devido aos elevados prejuízos econômicos decorrentes dos episódios de aborto eqüino e a inexistência de pesquisa etiológica nesta área no Estado do Paraná, os objetivos principais do presente trabalho foram os seguintes: determinação dos principais agentes causadores de aborto eqüino de origem infecciosa; tentativa de isolamento do Herpesvírus eqüino tipo 1 (EHV-1) a partir de órgãos fetais; e estudo da freqüência dos casos de aborto na região de Curitiba.

\section{Material e Métodos}

Os fetos foram coletados em haras próximos a Curitiba, em um raio de $70 \mathrm{~km}$, sendo a raça predominante o Puro Sangue Inglês (PSI). O manejo dos animais foi o habitualmente empregado nessas criações, com atenção maior a possíveis sinais premonitórios e indicativos de aborto. Após a ocorrência do aborto e no menor espaço de tempo possível, a coleta do material foi realizada obedecendo-se a seqüência abaixo: a) exame cuidadoso da placenta e colheita de fragmentos da mesma para exames histológico e bacteriológico; b) exame do cordão umbilical e colheita de fragmentos para histologia; e c) necropsia do feto e colheita de material para bacteriologia, virologia e histologia. Ao mesmo tempo era preenchido o protocolo de questões, composto dos seguintes ítens: município (localização), propriedade, nome da égua, idade, raça, alimentação, data e hora do aborto, hora da colheita, período de gestação, aborto gemelar ou único, garanhão pelo qual foi coberta, histórico reprodutivo, histórico de vacinação, outros abortos no haras, total de éguas prenhes, histórico de adubação e calagem nos piquetes, observações e resultado do exame do feto e placenta.

Para bacteriologia, foram colhidos fragmentos de pulmão, fígado e o conteúdo estomacal. Para virologia, foram colhidos fragmentos de timo, pulmão e fígado. Para histologia, foram colhidos fragmentos de timo, pulmão, fígado, baço, rim, intestino e coração; fixados em solução de Bouin ou formol a $10 \%$. O material colhido para bacteriologia e virologia foi acondicionado em recipientes estéreis e transportado até o laboratório em caixa de isopor com gelo. O material colhido para virologia foi armazenado em freezer a $-80{ }^{\circ} \mathrm{C}$, até o momento do processamento. $\mathrm{O}$ material colhido para bacteriologia foi semeado no menor espaço de tempo possível após a chegada ao laboratório, nos seguintes meios: ASA (Ágar Sangue) $\mathrm{CO}_{2} 10 \%$, MacConkey, Tetrationato, Sabouraud (para fungos) e Caldo BHI; do Tetrationato o material era repicado para Mac Conkey e do Caldo BHI repicado para Asa e Mac Conkey.

Para o diagnóstico laboratorial do Herpesvírus eqüino tipo 1 foram utilizadas as seguintes técnicas: impressão de lâminas para imunofluorescência, inoculação em cultivo celular e inoculação em camundongos. Culturas Celulares - a linhagem celular utilizada foi a VERO, proveniente do Instituto Adolfo Lutz, São Paulo. As células foram repicadas em meio mínimo de Eagle contendo 10\% de soro bovino adulto precipitado com polietilenoglicol. Amostras de Campo. Foram processados timo, pulmão e fígado de fetos abortados, provenientes da região de Curitiba. Animais de Laboratório. Foram utilizados, para a inoculação de amostras suspeitas, camundongos com 21 dias de idade e camundongos lactentes com 2 a 4 dias de idade. Virus Padrão. Foi utilizada a amostra A4/72, isolada na Seção de Raiva e Encefalomielite do Instituto Biológico de São Paulo, em 1972, a partir de órgãos de feto abortado, proveniente do município de Campinas, e adaptada à cultura de células VERO. Soro Padrão. Foi preparado em cobaias, através de inoculações, por via subcutânea, de 1000 DICT 50\%, da cepa A4/72. Uma semana após a última inoculação as cobaias foram sangradas, por punção cardíaca, e seu soro titulado pela técnica de fixação de complemento, segundo OSLER (1952). Conjugado Fluorescente. $\mathrm{O}$ soro hiperimune foi submetido à precipitação com sulfato de sódio, dialisado em solução salina, sendo posteriormente feita a dosagem da proteína pelo método do biureto, a purificação de $\operatorname{IgG}$ por cromatografia, o teste de especificidade pela imunoeletroforese e a marcação da $\operatorname{IgG}$ com isotiocianato de fluoresceína, segundo técnica preconizada por CAMARGO (1973). Preparo de 
Aspectos Etiológicos e Epidemiológicos do Aborto Eqüino

Amostras. O conjunto dos 3 fragmentos de órgãos fetais (timo, pulmão e fígado) foi pesado, objetivando-se calcular a quantidade necessária de meio de Eagle para o preparo de uma suspensão a $20 \%$. Com a utilização de um pistilo e pequena quantidade de areia estéril, procedeu-se à maceração do material e preparo da suspensão, que foi em seguida centrifugada a 3.000 r.p.m., durante 15 minutos em centrífuga refrigerada, para inoculação em sistemas sensíveis. Inoculação em cultivo celular. Células VERO, cultivadas em garrafas plásticas da marca COSTAR e também em lamínulas colocadas em tubos de Leigthon, foram inoculadas com o sobrenadante da suspensão centrifugada. A seqüência do processo é apresentada a seguir: a) após a retirada do meio de Eagle foi inoculado nas garrafas $1 \mathrm{ml}$ de suspensão a $20 \%$ e nos tubos $0,2 \mathrm{ml}$; b) incubação a $37{ }^{\circ} \mathrm{C}$, durante 1 hora, para que ocorra adsorção do vírus; c) o inóculo era dispensado; d) lavagem com Meio Mínimo de Eagle (MEM) sem soro bovino; e) colocação de MEM com 2\% de soro bovino: $5 \mathrm{ml}$ nas garrafas e $1 \mathrm{ml}$ nos tubos; e f) incubação em estufa a $37^{\circ} \mathrm{C}$ durante 18 horas. Técnica de Imunofluorescência Direta (KOTAIT et al., 1989). As lâminas preparadas a partir da impressão de órgãos e as lamínulas dos tubos de Leigthon, após fixação em acetona, durante 30 minutos, foram coradas com conjugado fluorescente e a leitura foi feita em microscópio de epiiluminação CARL ZEISS $^{\circledR}$, com aumento de 400X. Observe-se a descrição detalhada da técnica utilizada para as lâminas preparadas a partir da impressão de órgãos: a) após 17 horas de freezer a $-20^{\circ} \mathrm{C}$ as lâminas foram delimitadas com esmalte na região da impressão; b) em seguida, foram colocadas duas gotas da mistura 1 gota do conjugado preso +6 gotas de PBS com azul de Evans em cada lâmina (foram feitas duas lâminas de cada órgão); c) Incubação em estufa a $37^{\circ} \mathrm{C}$ durante 45 minutos, em câmara úmida; d) as lâminas foram retiradas da estufa e imersas em PBS pH 7,7 durante 10 minutos; e) as lâminas foram lavadas em água destilada três vezes e colocadas em estufa a $37{ }^{\circ} \mathrm{C}$ para secagem durante 20 minutos; e f) a parte de baixo das lâminas foi limpa com éter, em seguida foi colocada uma gota de glicerina tamponada em cada lâmina e, após isto, foram colocadas as lamínulas.

Observação. Controles positivos: cérebro, pulmão e fígado de Gerbil infectado com Herpesvírus eqüino tipo 1. Controles negativos: cérebros de cobaias. Inoculação de Animais. Cada suspensão de órgãos de feto abortado foi inoculada em 8 camundongos adultos e 8 camundongos lactentes. A inoculação foi via intra-cerebral, utilizando-se seringas descartáveis para insulina. Os camundongos adultos foram inoculados com 0,03 $\mathrm{ml}$ de suspensão e os camundongos lactentes, com $0,01 \mathrm{ml}$.

Método histológico. Os fragmentos de órgãos fetais e placenta, após fixação em formol a $10 \%$ ou solução de Bouin, foram recortados para processamento histológico de rotina. O material foi processado em um processador automático de tecidos-histotécnico OMAPV85, incluído em parafina, seccionado a $5 \mu \mathrm{m}$ de espessura e corado pela técnica da Hematoxilina de Harris-Eosina. Os cortes foram examinados ao microscópio óptico sob os aumentos de 40X, 100X, 400X e, sempre que necessário, 1000X sob imersão.

\section{Resultados e Discussão}

Índice de abortos. Durante os três anos do presente estudo foram acompanhadas 674 gestações, das quais 62 resultaram em aborto, o que equivale a $9,2 \%$, bastante próximo aos valores descritos na literatura. Trabalhos prévios de BAIN (1969), DU PLESSIS (1964) e SULLIVAN et al., (1975) têm indicado perdas na gestação após 45 dias variando de 11 a $19 \%$. Foram examinados 50 casos de aborto, sendo que em 23 a causa foi determinada, conforme se nota pelos resultados agrupados na Tab. 1.

Incidência de abortos por propriedade. As propriedades que apresentaram um número mínimo de 25 éguas gestantes por ano foram avaliadas individualmente, verificando-se uma variação de 2 a $25 \%$ na incidência de abortos por propriedade, em relação ao número de éguas gestantes.

Tabela 1.Etiologia dos casos examinados de aborto eqüino.

\begin{tabular}{l|c|c}
\hline ETIOLOGIA & CASOS (N $\left.{ }^{\circ}\right)$ & \% \\
\hline Não Identificada* & 27 & 54 \\
Bacteriana & 17 & 34 \\
Viral (Ehv-1) & 4 & 4 \\
Gestação Gemelar & 2 & 100 \\
\hline TOTAL & 50 & 8 \\
\hline
\end{tabular}

* Incluindo casos de autólise avançada, quando não foi colhido material para bacteriologia e virologia.

Idade média das éguas que abortaram. Analisou-se a idade de 52 éguas no momento do aborto e obteve-se uma média de 8,25 anos.

Abortos gemelares. Foram analisados 132 casos 
de aborto, incluindo casos de aborto em que as gestações não estavam sendo acompanhadas (propriedades não controladas), dos quais 6 foram gemelares, o que equivale a $4,5 \%$. Tais casos ocorreram, nos seguintes meses de gestação: $5^{\circ}, 6^{\circ}$, $7^{\circ}, 8^{\circ}$ e $10^{\circ}$ ( 2 casos $)$. Considerando a taxa encontrada de abortos de $9,2 \%$, o percentual encontrado de éguas prenhes que abortam gêmeos foi de $0,4 \%$. A literatura consultada (SWERCZEK, 1991b) afirma que entre 0,5 a $1 \%$ das éguas Puro Sangue Inglês abortam gêmeos ou, raramente, ambos vivos a termo. Os abortos gemelares geralmente são observados após o $8^{\circ}$ mês de gestação, apesar de que já foram descritos casos com 88 dias (JEFFCOTT e WHITWELL, 1974; WHITWELL, 1980).

Isolamento do Herpesvírus eqüino tipo 1. $\mathrm{O}$ material de 21 fetos foi processado com o intuito de isolar-se o Herpesvírus eqüino tipo 1, obtendo-se o isolamento em 4 casos, através da utilização da técnica de inoculação em cultivo celular da linhagem VERO e de provas de imunofluorescência. Com relação ao período de gestação, estes abortos ocorreram no $5^{\circ}, 6^{\circ}, 8^{\circ}$ e $9^{\circ}$ mês.

Bactérias isoladas dos fetos abortados. Foram processados para bacteriologia um total de 38 fetos, dos quais 17 foram considerados positivos. Os critérios adotados para considerar-se um feto, bacteriologicamente positivo foram aqueles sugeridos por ROSSDALE e RICKETTS (1976). As bactérias isoladas dos casos positivos estão descritas na Tab. 2. Verificou-se que as bactérias isoladas nesta pesquisa nos casos de aborto de origem bacteriana, correspondem àquelas comumente citadas na literatura (ACLAND, 1987; MAHAFFEY, 1968; PRICKETT, 1970; LANGFORD, 1974; DIMOCK et al., 1947).

Prevalência mensal dos casos de aborto. Para melhor visualização, os resultados da freqüência de abortos em relação ao mês do ano, foram distribuídos na Fig. 1. Os meses em que foi observada maior incidência de casos de aborto (março a agosto), correspondem aos meses em que as éguas apresentam-se no terço final da gestação, em decorrência da estação de monta definida para a raça Puro Sangue Inglês, que compreende o período de 15 de agosto a 15 de janeiro.

Tabela 2.Casos de aborto de origem bacteriana em eqüinos.

\begin{tabular}{l|c|c}
\hline AGENTE & $\mathbf{N}^{\mathbf{0}}$ CASOS & \% \\
\hline Streptococcus spp. $\beta$ - hemolítico & 3 & 17,6 \\
Streptococcus spp. $\alpha$ - hemolítico & 1 & 5,9 \\
Streptococcus spp. não hemolítico & 1 & 5,9 \\
Escherichia coli & 2 & 11,8 \\
Pseudomonas spp. & 2 & 11,8 \\
Staphylococcus spp. & 2 & 11,8 \\
Klebsiella spp. & 2 & 11,8 \\
Klebsiella pneumoniae & 1 & 5,9 \\
Actinobacillus equuli & 1 & 5,9 \\
Enterobacter cloacae & 1 & 5,9 \\
Bacillus spp. & 1 & 5,9 \\
\hline TOTAL & 17 & 100,0 \\
\hline
\end{tabular}

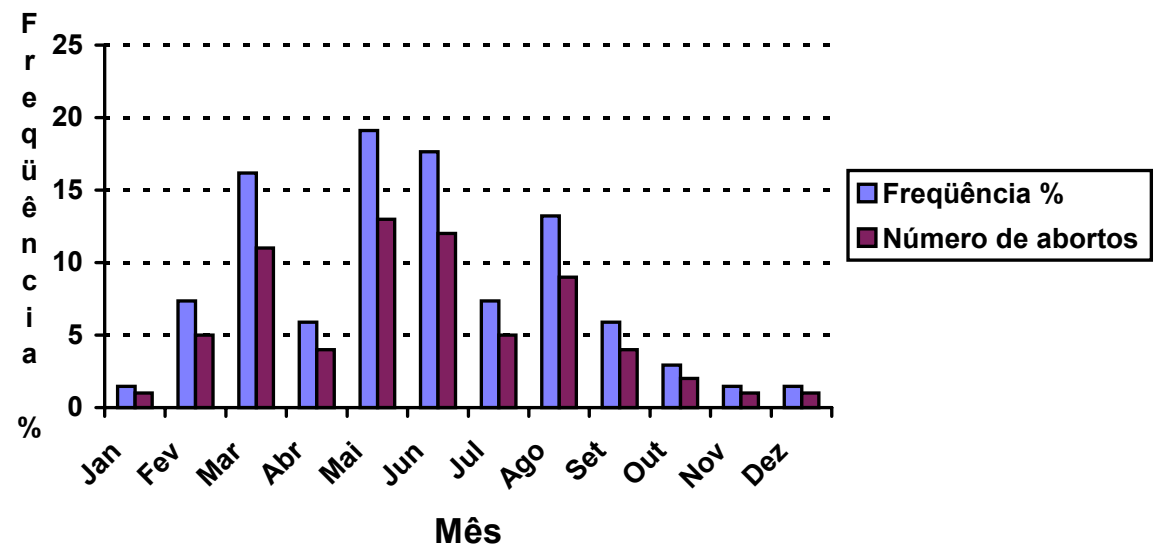

Fig. 1. Prevalência mensal dos casos de aborto eqüino. 
Prevalência dos casos de aborto segundo o período de gestação. Para melhor visualização, os resultados da freqüência de abortos em relação ao período de gestação, foram distribuídos na Fig. 2. $\mathrm{Na}$ análise do período de gestação (terço final), que apresentou maior prevalência de casos de aborto, verificou-se que coincide com o citado por MACRUZ (1991), em fetos examinados no Jockey Club de São Paulo e no Instituto Biológico de São Paulo.

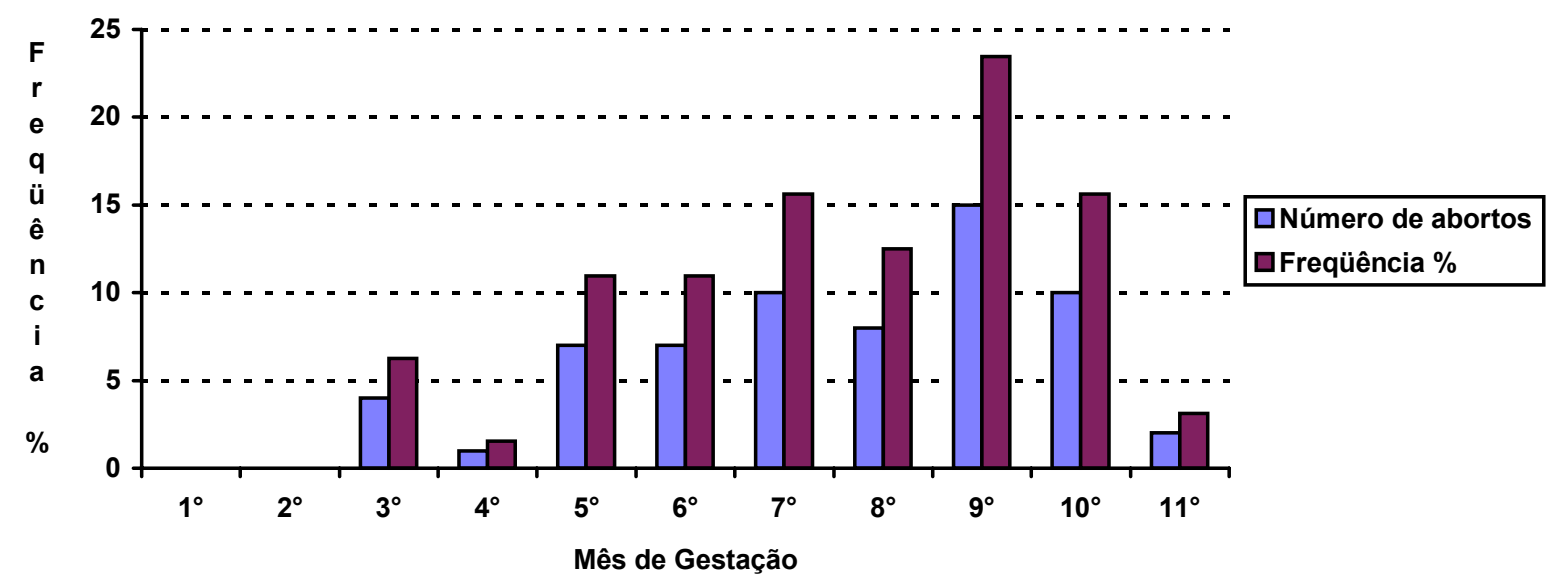

Fig. 2. Freqüência de abortos em relação ao período de gestação em eqüinos.

Exame histológico. As alterações encontradas no exame histológico dos casos de aborto estão resumidas a seguir: Casos de origem bacteriana: Placenta: edema, hiperemia, infiltração por polimorfonucleares, dilatações císticas, placentite purulenta. Fígado: hiperemia acentuada, autólise, fibrose periductal nos espaços porta com infiltração por polimorfonucleares. Intestino: edema na submucosa, algumas vezes com infiltração leucocitária. Casos de origem viral (Herpesvírus eqüino tipo 1): Fígado: desarranjo e tumefação das trabéculas hepáticas, leve megalocitose, infiltração por monomorfonucleares e raros polimorfonucleares. Rins: edema intersticial. Pulmão: hiperemia intensa. Placenta: infiltração por monomorfonucleares e polimorfonucleares, placentite subaguda. Cordão umbilical: onfaloflebite aguda com infiltração eosinofílica e presença de alguns neutrófilos.

Tais alterações não estavam presentes em todos os casos, mas, sim, representam um compilado das alterações encontradas com relativa freqüência. Por outro lado, o exame histológico foi algumas vezes prejudicado por certo grau de autólise intra ou extra-uterina.

\section{Conclusões}

Dos casos processados para bacteriologia, $44,7 \%$ resultaram positivos. As bactérias isoladas como agentes etiológicos de abortos foram as mesmas freqüentemente isoladas em casos de endometrite na égua, sugerindo então a via ascendente de contaminação. Por outro lado, $19,0 \%$ dos casos processados para virologia resultaram positivos. Os casos de isolamento do Herpesvírus eqüino tipo 1, a partir de órgãos fetais, vieram a comprovar sua participação como agente etiológico de abortos na população estudada. Em relação aos casos de aborto relatados neste trabalho, 4,5\% foram identificados como gemelares.

Com o objetivo de evitar-se, tanto quanto possível, os casos de aborto eqüino, são propostas as seguintes sugestões: a) todo caso de aborto deve ser considerado como uma possível fonte de infecção; b) o feto e a placenta, após a necropsia e colheita de material, devem ser incinerados e, se possível, enterrados; c) as áreas de cocheira contaminadas por sangue ou fluidos fetais devem ser desinfetadas e a cama incinerada; d) o posterior da égua deve ser limpo com uma solução desinfetante; e) a égua que abortou deve ser isolada das outras éguas prenhes. O contato indireto, seja através de pessoal ou de utensílios, deve ser evitado; f) a introdução de novos animais no grupo de éguas prenhes deve ser evitada; g) os exames vaginais e cervicais devem ser feitos com espéculo tubular que possua o menor diâmetro possível. Com relação a esta sugestão cita-se como exemplo o trabalho de MAHAFFEY (1968) onde afirma nunca ter encontrado aborto fúngico em pôneis que nunca foram submetidas a exames ginecológicos; $h$ ) atentar para as condições básicas de nutrição, manejo e sanidade; e, finalmente, i) a metodologia 
utilizada neste trabalho poderá servir como referência na investigação dos casos de aborto eqüino e no aprimoramento das técnicas de diagnóstico.

\section{Agradecimentos}

Ao Instituto Biológico de São Paulo, pela colaboração no estudo virológico dos casos de aborto.

\section{REFERÊNCIAS BIBLIOGRÁFICAS}

ACLAND, H.M. Abortion in mares: diagnosis and prevention. Comp Equine. 9(3):318-324, 1987.

BAIN, A.M. Foetal losses during pregnancy in the Thoroughbred mare: a record of 2562 pregnancies. $N$. Z. Vet. 17:155-158, 1969.

CAMARGO, M.E. Introdução às técnicas de imunofluorescência. São Paulo: Instituto de Medicina Tropical, 1973, 114 p. Boletim Técnico.

DIMOCK, W.W., EDWARDS, P.R., BRUNNER, D.W. Infections of fetuses and foals. Bull Ky. Agric. Exp. Stn. p. 509, 1947.

DU PLESSIS, J.L. Some observations and data in Thoroughbred breeding. J. So. Afr. Vet. Med. Assoc. 35:215-221, 1964.

FERNANDES, W.R. Determinação da infecção por Herpesvírus eqüino tipo $1 \mathrm{em}$ animais criados no Estado de São Paulo, através da reação de fixação de complemento. Faculdade de Medicina Veterinária e Zootecnia da Universidade de São Paulo. SP, 1988.

JEFFCOTT, L.B., WHITWELL, K.E. Twinning as a cause of fetal and neonatal loss in the Thoroughbred mare. J. Comp. Path. 83:91-106, 1974.

KOTAIT, I., PEIXOTO, Z.M.P., QUEIROZ, L.H. et al. Diagnóstico laboratorial do aborto eqüino a vírus através de imunofluorescência e soroneutralização. Rev. Microbiol. 20(1):128-132, 1989.

LANGFORD, E.V. Isolation of Mycoplasma bovigenitalium from an aborted equine foetus. Vet. Rec. 94:528, 1974.

MACRUZ, R. Incidência de abortos eqüinos e diagnóstico anátomo-histológico. Anais Vol II/ IX Congresso Brasileiro de Reprodução Animal, Belo Horizonte: Colégio Brasileiro de Reprodução Animal, p. 91-99, 1991.
MAHAFFEY, L.W. Abortion in mares. Vet. Rec. 15:681$687,1968$.

MODOLO, J.R., PETZOLDT, K., GOTTSCHALK, A.F., MARGATHO, L.F.F., FORLIN, W., CARREIRA, E.L.C. Investigação sorológica do Herpesvirus equi 1 em eqüinos pelo teste de fixação de complemento, considerações sobre seu uso na saúde do haras. $A$ Hora Veterinária. 488:25-27, 1989.

MOREIRA, N. Investigação das causas de aborto eqüino. Tese de Mestrado Curso de Pós-Graduação em Ciências Veterinárias, Universidade Federal do Paraná, PR, Brasil, 1992.

NILSON, M.R., CORREAA, W.M. Isolamento do vírus do aborto eqüino no Estado de São Paulo. Arq. Inst. Biol. 33(2):23-25, 1966.

OSLER, A.G., STRAUSS, J.H., MAYER, M.M. Diagnostic complement fixation. I. A method. Am. J. Syph. 36:140-153, 1952.

PRICKETT, M.E. Abortions and placental lesions in the mare. JAVMA. 157:1465-1470, 1970.

ROSSDALE, P.D., RICKETTS, S.W. Equine abortion. Vet. Ann. 16:133-141, 1976.

SULLIVAN, J.J., TURNER, P.C., SELF, L.C., GUTTERIDGE, H.B., BARTLETT, D.E. Survey of reproductive efficiency in the Quarter-horse and Thoroughbred. J. Reprod. Fert. Suppl. 23:315-318, 1975.

SWERCZEK, T.W. Recognizing the common causes of equine abortion: An overview. Vet. Med. p. 10191024, 1991a.

SWERCZEK, T.W. Noninfectious causes of abortion in the mare. Vet. Med. p. 1025-1029, 1991b.

VARGAS, A.P.C. Herpesvírus eqüino tipo 1: prevalência em eqüinos no Estado do Rio Grande do Sul, Brasil. Universidade Federal de Santa Maria, RS, Brasil, 1989.

WEIBLEN, R., RABUSKE, M., REBELATTO, M.C., NOBRE, V.M.T., CANABARRO, T.F. Abortions due to equine herpesvirus in Southern Brazil. Brazilian J. Med. Biol. Res. 27:13171320, 1994.

WHITWELL, K.E. Investigations into fetal and neonatal losses in the horse. Vet. Clin. North. Am., Lrg. Animl. Pract. 2:313-329, 1980.

WITHERSPOON, D.M. Vaccination against equine herpesvirus 1 and equine influenza infection. Vet. Rec. 115(14):363,1984. 